\title{
Platelet-rich plasma versus combined fractional carbon dioxide laser with platelet-rich plasma in the treatment of vitiligo: a comparative study
}

This article was published in the following Dove Press journal:

Clinical, Cosmetic and Investigational Dermatology

\author{
Mostafa Kadry' \\ Abeer Tawfik ${ }^{2}$ \\ Noha Abdallah ${ }^{2}$ \\ Ashraf Badawi $i^{2,3}$ \\ Hisham Shokeir ${ }^{2}$ \\ 'Faculty of Medicine, Dermatology \\ Department, Helwan University Cairo, \\ Helwan, Egypt; ${ }^{2}$ Dermatology Unit, \\ Department of Medical Applications \\ of Lasers (MAL), National Institute \\ of Laser Enhanced Sciences, Cairo \\ University, Giza, Egypt; ${ }^{3}$ Department \\ of Allergology and Dermatology, \\ Szeged University, Hungary
}

Purpose: The aim of this study was to assess the efficacy of platelet-rich plasma (PRP) vs combined fractional $\mathrm{CO}_{2}\left(\mathrm{Fr}: \mathrm{CO}_{2}\right)$ laser with PRP in the treatment of stable nonsegmental vitiligo (NSV) lesions.

Patients and methods: This prospective, randomized, intrapatient, comparative controlled study was conducted between June 2014 and June 2016 at National Institute of Laser Enhanced Sciences (NILES), Cairo University, Cairo, Egypt. Thirty NSV patients were treated with PRP, Fr: $\mathrm{CO}_{2}$ laser, and combined Fr: $\mathrm{CO}_{2}$ laser with PRP. Intrapatient lesions were divide randomly into four groups. Each group was treated by one modality. The fourth group served as a control. Patients received six treatment sessions with 2-week interval for 3 months and were followed up after 3 months.

Results: A highly significant reduction was demonstrated through vitiligo analysis by computerassisted grid (VACAG) in the combined Fr: $\mathrm{CO}_{2}$ laser with PRP and in the PRP only groups than other groups. These results were confirmed by mean improvement score by physician (MISP) and by VAS with no statistical difference between them. The combined Fr: $\mathrm{CO}_{2}$ laser with PRP group showed minimal side effects. Regardless of the modalities, better improvement was seen in the trunk than the face, extremities, and acral lesions with significant reduction in all regions. Face showed maximum response with combined $\mathrm{Fr}$ : $\mathrm{CO}_{2}$ laser with PRP. Trunk showed higher response with PRP. Upper limbs showed highest response with combined Fr: $\mathrm{CO}_{2}$ laser with PRP. Lower limbs showed the highest improvement with Fr: $\mathrm{CO}_{2}$ laser.

Conclusion: According to our study, combined Fr: $\mathrm{CO}_{2}$ laser with PRP achieved superior repigmentation than intradermal (ID) PRP. However, Fr: $\mathrm{CO}_{2}$ alone showed poor improvement Combined ablative Fr: $\mathrm{CO}_{2}$ laser and PRP therapy followed by sun exposure could be used effectively and safely to treat refractory NSV.

Keywords: platelet-rich plasma, fractional carbon dioxide laser, melanoblasts, stem cells, nonsegmental vitiligo, refractory vitiligo, vitiligo, undifferentiated stem cell

\section{Introduction}

Vitiligo is a skin disorder occurring in about $0.5 \%-2 \%$ of the population. ${ }^{1}$ The treatment of choice is still controversial. Several combination therapies have been introduced to obtain better results and to reduce risks. ${ }^{2}$ The prolonged duration of therapy is the main reason for patient noncompliance. ${ }^{3}$ Platelet-rich plasma (PRP) is composed of high concentration of platelets with high concentration of growth factors (GFs). ${ }^{4}$ This may help in stimulation of the proliferation of melanocytes and repigmentation within vitiliginous patches. ${ }^{5}$ Ablative treatment options such as fractional $\mathrm{CO}_{2}\left(\mathrm{Fr}: \mathrm{CO}_{2}\right)$ laser
Correspondence: Ashraf Badawi Dermatology, Laser Institute, Cairo University, Dermatology and Laser applications, Szeged 2147 Mayflower Blvd., Oakville, ON L6H4E6 Email ashrafbadawi@hotmail.com 
were introduced as a treatment modality for vitiligo. ${ }^{6,7} \mathrm{After}$ Fr: $\mathrm{CO}_{2}$ laser therapy, various types of cytokines and GFs were secreted during the wound healing process. ${ }^{8}$

The aim of this study is to evaluate the effect of PRP vs Fr: $\mathrm{CO}_{2}$ and combined Fr: $\mathrm{CO}_{2}$ with PRP followed by sun exposure in the treatment of stable nonsegmental vitiligo (NSV).

\section{Patients and methods}

This is a prospective, randomized, intrapatient, comparative, controlled study. It was conducted from June 2014 to June 2016 at National Institute of Laser Enhanced Sciences (NILES), Cairo University, Cairo, Egypt. Ethical approval was obtained from research ethical committee. The study protocol conformed to the guidelines of the Declaration of Helsinki. A written and informed consent was obtained from all the patients before study enrollment for both participation and publication of images.

Eighty-three patients presented with NSV. They were assessed for eligibility according to the defined inclusion and exclusion criteria. ${ }^{9}{ }^{10}$ Thirty patients were eligible to participate in this study. They were recruited from Dermatology Outpatient Clinic, NILES, Cairo University, Egypt.

Patients were instructed to avoid using any other modalities of treatment for NSV during the course of the study. Patients included were older than 18 years, presenting with more than four lesions of stable, nonprogressive NSV with the absence of new lesions or enlargement of the preexisting lesions for the past 12 months. Pregnant women and patients on local medications or laser therapy 1 month prior to their enrollment were excluded. Also, patients with bleeding disorders, history of keloid formation, koebnerization, photosensitivity, and seizure disorders were not enrolled in the study.

Intrapatient lesions were randomly divided into four groups according to the treatment modality: PRP group, combined Fr: $\mathrm{CO}_{2}$ with PRP group, Fr: $\mathrm{CO}_{2}$ group, and control group. Patients received six treatment sessions with 2-week interval for 3 months and were followed up after 3 months.

\section{PRP group}

Thirty lesions were treated by Sterfile European Conformity (CE) marked RegenLab ${ }^{\circledR}$ kit (Regen Lab SA, Le Mont-surLausanne, Switzerland). Eight milliliters of blood sample was aspirated from the patient's peripheral vein, and the sample was centrifuged at 1,500 rpm for 5 minutes. A 30-G needle was used for superficial intradermal (ID) microinjections (0.1 $\mathrm{mL}$ per injection and spaced about $1 \mathrm{~cm}$ apart). ${ }^{4}$

\section{Fr: $\mathrm{CO}_{2}$ group}

Thirty lesions were treated by Fr: $\mathrm{CO}_{2}$ laser $(10,600 \mathrm{~nm}$; KES Corporation, Beijing, China). A test dose was done prior to treatment, and the minimum energy (30-50 mJ) was chosen to induce erythema. Scanner spot size was adjusted based on the lesion size. Density selected was 0.6 in the static mode. Two passes with minimal overlap were delivered. The laser was applied to the vitiligo lesion and over a thin rim of healthy skin $(2 \mathrm{~mm}) .{ }^{11}$ After the laser treatment, Fucidin cream ${ }^{\circledR}$ (Fusidic 2\%; LEO Pharmaceuticals, Ballerup, Denmark) was applied twice daily for 1 week.

\section{Combined $\mathrm{Fr}: \mathrm{CO}_{2}$ with PRP group}

Thirty lesions were treated by Fr: $\mathrm{CO}_{2}+\mathrm{ID}$ PRP injection.

\section{Control group}

Thirty lesions were left as control.

All patients were asked to expose the treated lesions as well as one of the control lesions to sun for 2 hours daily (between 5-7 am and 4-6 pm). Also, they were asked to notice and report any adverse effects.

\section{Evaluation methods}

\section{Vitiligo analysis by computer-assisted grid (VACAG)}

A transparent grid was used for the calculation of changes in the vitiligo patch size. The number of intersections covering the lesion was counted as shown in Figure $1 .{ }^{12}$

To obtain accurate measurement of localized vitiligo lesions, the borders of the lesions were marked by manually tracking the lesions onto the transparent graph paper. To estimate the number of points, the number of intersections hitting the area of interest was counted. The total area of each lesion was estimated by multiplying the representative area of a point on grid by total number of points counted for the lesion.

This was performed on a computer assisted grid "point counting and digital planimetry technique" by AutoCAD 2016, version 20.1 released on March 23, 2015, developed and marketed by Autodesk Incorporation, USA.

Nikon D5300 camera (Nikon Corporation, Tokyo, Japan), a 24.2 megapixels digital single-lens reflex (DSLR) camera with 18-55 mm lens, was used. Photographs were obtained at baseline, at each session, and at 3 months after the end of the treatment for follow-up using identical camera settings, lighting, background, and patient positioning to ensure the consistency of images. 

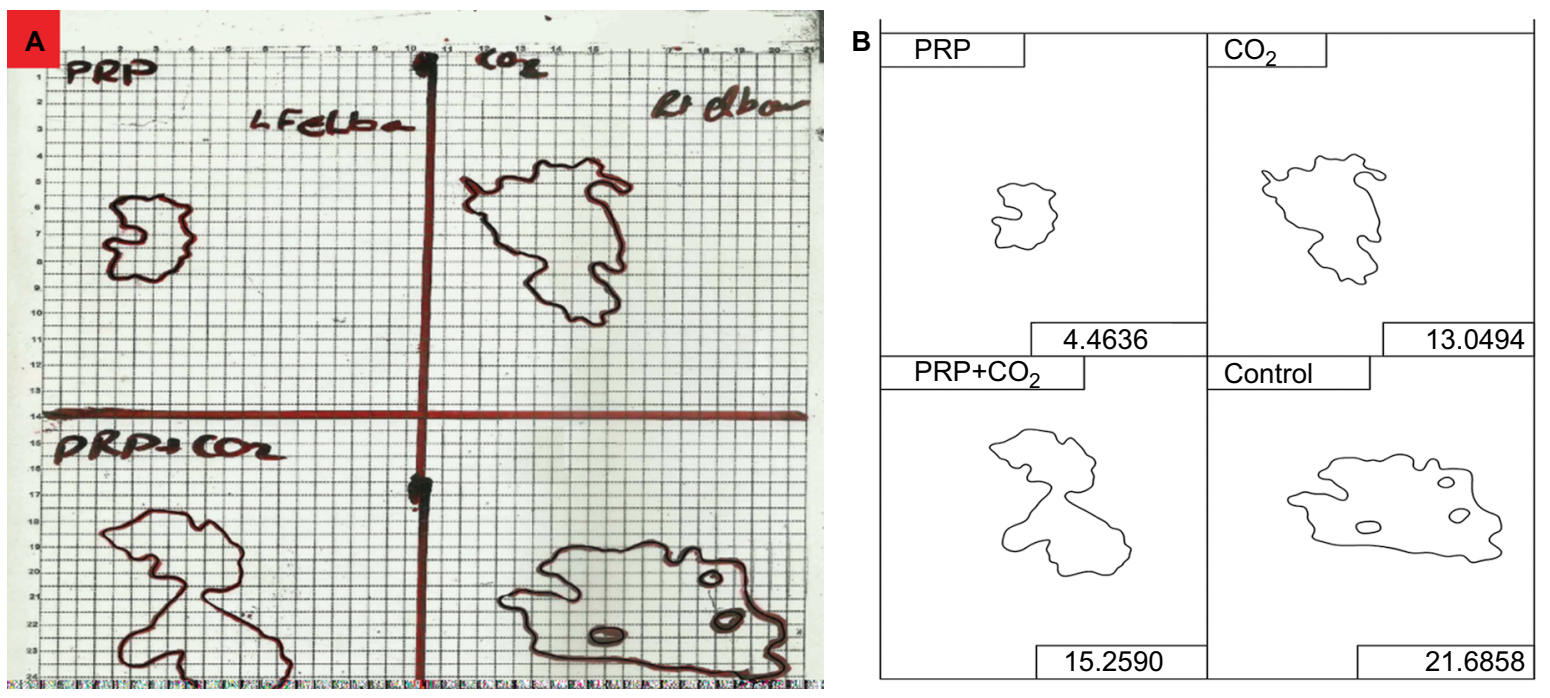

Figure I (A) Point counting: example grid for vitiligo lesion. The total area of the lesion was estimated by multiplying $0.1 \mathrm{~cm}^{2}$ by the number of points. (B) Digital planimetry technique: calculation of changes in the vitiligo patch size by AutoCAD 2016, version 20.1. Abbreviation: PRP, platelet-rich plasma.

\section{Mean improvement score by physician (MISP)}

MISP was calculated by comparing the photographs. Physicians' clinical assessments were done by two blinded dermatologists using a quartile grading scale (grade $1:<25 \%$, no or minimal improvement; grade $2: 25 \%-49 \%$, moderate; grade 3: $50 \%-74 \%$, marked; grade $4:>75 \%-99 \%$, excellent; and grade 5: $100 \%$, complete). ${ }^{6}$

\section{Patient's satisfaction}

Patients rated their satisfaction at the end of the study for overall rates of satisfaction and side effects of treatment using a 10-point VAS (0-10; the 0 level was defined as "not satisfied at all," whereas the level of 10 was defined as "completely satisfied"). Evaluation was done at baseline (VAS0) and 3 months after the final session (VAS3m) ${ }^{6,13,14}$

\section{Histopathological study}

Punch biopsy specimens of $4 \mathrm{~mm}$ were taken from the lesion sites before and after the end of treatment from each lesion of 10 patients.

Biopsies were obtained to evaluate histological findings and were stained with H\&E and HMB45 for each treatment modality. Prominent melanin pigmentation and expression of HMB45 were assessed.

\section{Ethics statement}

The patients provided written informed consent for the publication of the images. Also informed consent was obtained from all individual participants included in the study, and the study was approved by the ethical committee of the Dermatology Department.

\section{Statistical analyses}

Data were coded and entered using the SPSS version 24. Data were summarized as median and IQR for quantitative data and as frequency (count) and relative frequency (percentage) for categorical data. Comparisons between quantitative variables were done using the nonparametric Kruskal-Wallis and Mann-Whitney tests. For comparison of paired measurements within each patient, the nonparametric Friedman test and Wilcoxon signed-rank test were used. ${ }^{15}$ Correlations between quantitative variables were done using Spearman correlation coefficient. ${ }^{16}$ Testing for interrater reliability was done using the intraclass correlation coefficient (ICC) and Cronbach's alpha reliability coefficient with their $95 \%$ CIs. ${ }^{17} P$-values less than 0.05 were considered as statistically significant.

\section{Results}

Thirty patients participated in this study: 22 (73.4\%) female patients and eight $(26.7 \%)$ male patients. Their ages ranged from 18 to 59 years (mean \pm SD, $32.03 \pm 12.29$ years). The disease duration ranged from 6 to 120 months (median, 12 months). The descriptive data of patients and NSV lesions are shown in Table 1.

Variable results of improvement were obtained in the four groups. Both the combined Fr: $\mathrm{CO}_{2}$ with PRP group and PRP group showed the highest significant improvement when compared to other modalities $(P<0.001$; Table 2$)$. There was a dramatic decrease in the surface area of vitiligo in 
Table I Demographic data of patients and lesions

\begin{tabular}{|c|c|c|c|c|c|c|}
\hline Demographic data & & & & & & \\
\hline \multirow[t]{2}{*}{ Age (years) } & From & To & Mean \pm SD & & & \\
\hline & 18 & 59 & $32.03 \pm 12.29$ & & & \\
\hline \multirow[t]{3}{*}{ Sex } & Description & $\mathbf{n}$ & $\%$ & & & \\
\hline & Female & 22 & 73.4 & & & \\
\hline & Male & 8 & 26.7 & & & \\
\hline \multirow[t]{5}{*}{ Site } & Description & $n$ & $\%$ & & & \\
\hline & Face & 40 & 33.3 & & & \\
\hline & Trunk & 12 & 10 & & & \\
\hline & Upper limb & 46 & 38.3 & & & \\
\hline & Lower limb & 22 & 18.3 & & & \\
\hline \multirow[t]{2}{*}{ Duration (months) } & From & To & Mean \pm SD & Median & First quartile & Third quartile \\
\hline & 6 & 120 & $22.53 \pm 23.75$ & 12.00 & 10.00 & 24.00 \\
\hline \multirow[t]{4}{*}{ Skin type } & Description & $\mathbf{n}$ & $\%$ & & & \\
\hline & II & 1 & 3.3 & & & \\
\hline & III & 20 & 66.7 & & & \\
\hline & IV & 9 & 30 & & & \\
\hline
\end{tabular}

Table 2 Results of VACAG, MISP, and VAS

\begin{tabular}{|c|c|c|c|c|c|c|c|}
\hline & \multirow[t]{2}{*}{ Mean \pm SD } & \multirow[t]{2}{*}{ Median } & \multirow{2}{*}{$\begin{array}{l}\text { First } \\
\text { quartile }\end{array}$} & \multirow{2}{*}{$\begin{array}{l}\text { Third } \\
\text { quartile }\end{array}$} & & \multicolumn{2}{|c|}{ Kruskal-Wallis test } \\
\hline & & & & & & $P$-value & Significance \\
\hline \multicolumn{8}{|l|}{ Surface area reduction } \\
\hline PRP of reduction & $57.01 \pm 29.67$ & 53.05 & 31.45 & 91.63 & & \multirow[t]{4}{*}{$<0.001$} & \multirow[t]{4}{*}{$\mathrm{H}$ significant } \\
\hline $\mathrm{CO}_{2}+\mathrm{PRP}$ of reduction & $54.22 \pm 37.08$ & 56.83 & 21.99 & 88.89 & & & \\
\hline $\mathrm{CO}_{2}$ of reduction & $38.08 \pm 36.43$ & 38.12 & 19.49 & 61.12 & & & \\
\hline Control of reduction & $13.79 \pm 40.32$ & 2.95 & -0.48 & 38.97 & & & \\
\hline MISP & Mean \pm SD & Median & $\begin{array}{l}\text { First } \\
\text { quartile }\end{array}$ & $\begin{array}{l}\text { Third } \\
\text { quartile }\end{array}$ & $\begin{array}{l}\text { Intraclass } \\
\text { correlation } \\
\text { coefficient }\end{array}$ & & \\
\hline PRP & $2.97 \pm 1.16$ & 3.00 & 2.00 & 4.00 & 0.957 & \multirow[t]{4}{*}{$<0.001$} & \multirow[t]{4}{*}{$\mathrm{H}$ significant } \\
\hline $\mathrm{CO}_{2}+\mathrm{PRP}$ & $3.20 \pm 1.27$ & 3.50 & 2.00 & 4.00 & 0.964 & & \\
\hline $\mathrm{CO}_{2}$ & $2.30 \pm 1.27$ & 2.00 & 2.00 & 3.00 & 0.940 & & \\
\hline Control & $1.20 \pm 0.55$ & 1.00 & 1.00 & 1.00 & 0.869 & & \\
\hline VAS & Mean \pm SD & Median & $\begin{array}{l}\text { First } \\
\text { quartile }\end{array}$ & $\begin{array}{l}\text { Third } \\
\text { quartile }\end{array}$ & & & \\
\hline PRP & $6.67 \pm 2.37$ & 7.00 & 5.00 & 9.00 & & \multirow[t]{4}{*}{$<0.001$} & \multirow[t]{4}{*}{ H significant } \\
\hline $\mathrm{CO}_{2}+\mathrm{PRP}$ & $6.87 \pm 2.65$ & 7.50 & 5.00 & 9.00 & & & \\
\hline $\mathrm{CO}_{2}$ & $4.87 \pm 2.19$ & 5.00 & 4.00 & 6.00 & & & \\
\hline Control & $1.30 \pm 1.91$ & 0 & 0 & 2.00 & & & \\
\hline
\end{tabular}

Abbreviations: $\mathrm{H}$, highly; MISP, mean improvement score by physician; PRP, platelet-rich plasma; VACAG, vitiligo analysis by computer-assisted grid.

the group treated with combined Fr: $\mathrm{CO}_{2}$ with PRP. On the other hand, the PRP group showed moderate improvements. Unexpectedly, mild improvements were observed in the Fr: $\mathrm{CO}_{2}$ group (Figure 2).

There was a statistically significant difference in repigmentation grade, MISP, and VAS among the combined Fr: $\mathrm{CO}_{2}$ with PRP group, the PRP group, and other groups $(P<0.001 ;$ Kruskal-Wallis test).

Regarding the site, the most significant improvement was observed in the trunk followed by the face, the upper limb (UL), and the lower limb (LL), which was the most resistance site (Figure 3).
The mean values of VACG, MISP, and VAS in each group are summarized in Table 2.

In combined Fr: $\mathrm{CO}_{2}$ with PRP group, the median values of repigmentation, MISP, and VAS were 56.83, 3.50, and 7.50 , respectively.

Lesions over the face showed best response followed by acral lesions and truncal lesions. Feet and LL lesions showed less response (Table 3).

Regarding PRP group, the median values of repigmentation, MISP, and VAS were 53.05, 3.00, and 7.00, respectively. Lesions over the trunk showed best response followed by lesions over face and acral. Extremities and LL lesions 

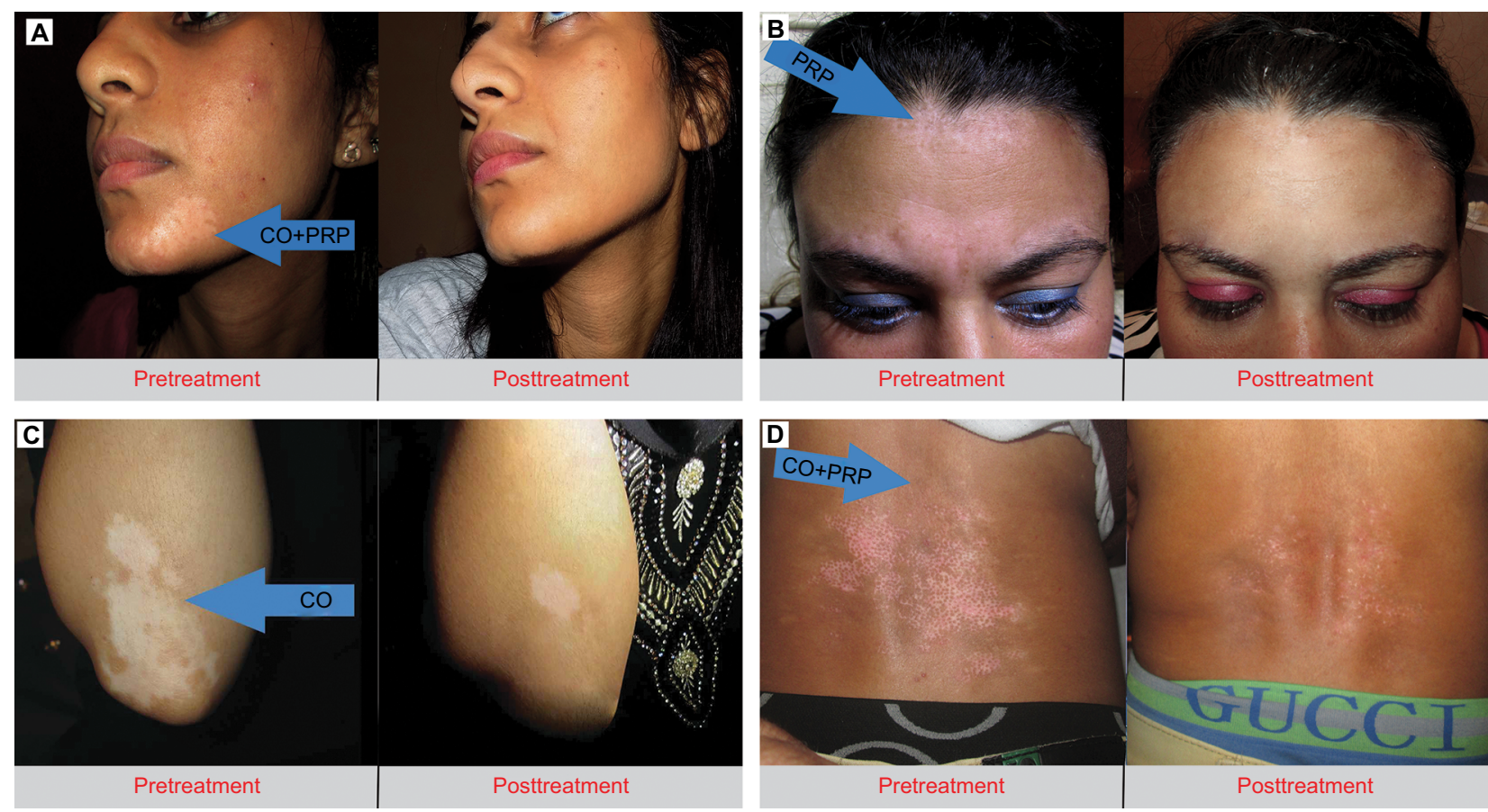

Figure 2 Variable results of improvement of vitiligo.

Notes: (A) A 22-year-old female patient, skin type III with 3 years duration of vitiligo lesions. Pretreatment and posttreatment images showing lower left chin treatment with combination of $\mathrm{Fr}$ : $\mathrm{CO}_{2}+$ PRP. (B) A 38-year-old female patient, skin type III with 12 months duration of vitiligo lesions. Pretreatment and posttreatment images showing upper forehead treatment with PRP. (C) A 21 -year-old female patient, skin type II with 26 months duration of vitiligo lesions. Pretreatment and posttreatment images showing right elbow treatment with $\mathrm{CO}_{2}$. (D) A 26-year-old male patient, skin type III with 14 months duration of vitiligo lesions. Pretreatment and posttreatment images showing back with $\mathrm{PRP}+\mathrm{CO}_{2}$.

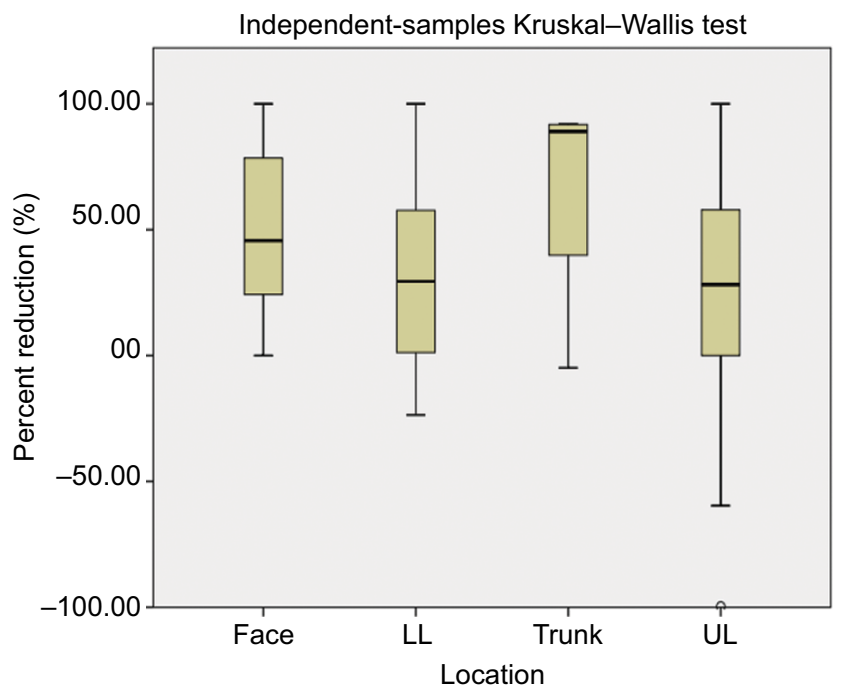

Figure 3 Relationship between degree of improvement and sites in all groups together.

Abbreviations: LL, lower limb; UL, upper limb.

showed no response. In laser group, the median values of re-pigmentation, MISP, and VAS were 38.12, 2.00, and 5.00, respectively. Lesions over the trunk showed best response followed by lesions over extremities and face. Acral lesions showed no response.
All modalities showed agreement between physicians and confirmed by interrater reliability agreement, ICC, and Cronbach's alpha.

The correlation between the percent of the reduction of surface area and different variable "sex, age, skin type and duration of the disease" were done. Inverse significant correlation was found between the disease duration and the percentage of reduction confirmed by $P$-value and correlation coefficient.

\section{Side effects}

The most common adverse event was pain. It was observed more commonly in the Fr: $\mathrm{CO}_{2}$ group and the PRP group (33.3\%) compared with that in the combined Fr: $\mathrm{CO}_{2}$ with PRP group (23.33\%). Hyperpigmentation occurred in the Fr: $\mathrm{CO}_{2}$ (26.66\%) and combined Fr: $\mathrm{CO}_{2}$ with PRP groups (6.66\%).

Other less common side effects included inflammation that developed in the Fr: $\mathrm{CO}_{2}$ group and the combined Fr: $\mathrm{CO}_{2}$ with PRP group. Ecchymosis in the PRP and combined Fr: $\mathrm{CO}_{2}$ with PRP groups lasted for 3-5 days. None of the study subjects developed koebnerization. No patients showed recurrence. 


\section{Histopathological evaluation}

Before treatment, sections stained with H\&E revealed complete absence of melanin pigmentation. However, after the end of treatment with PRP and combined Fr: $\mathrm{CO}_{2}$ with PRP, the H\&E-stained sections revealed the expression of prominent melanin pigment (Figure 4A-C). After the treatment with Fr: $\mathrm{CO}_{2}$, histopathological examination revealed weak melanin pigmentation as shown in Figure 4D.

Before treatment, H\&E-stained sections revealed negative expression for HMB45. However, after the end of treatment with PRP and combined Fr: $\mathrm{CO}_{2}$ with PRP, histopathological specimens revealed marked expression of HMB45 (Figure 4E-G). After treatment with Fr: $\mathrm{CO}_{2}$, histopathological examination revealed moderate melanin expression as shown in Figure 4H.

\section{Discussion}

None of the current modalities of treatment can improve NSV completely. Currently, available modalities specifically target the NSV and elicit high response rates. However, the majority of patients eventually develops progressive course. The mechanism of the new modalities such as Fr: $\mathrm{CO}_{2}$ and PRP is not well evaluated yet in recalcitrant NSV treatment. Introduction of these new treatments of NSV might be an alternative to current available therapies. Hence, a new treatment and a combined approach are required. ${ }^{6}$

This study demonstrated that Fr: $\mathrm{CO}_{2}+\mathrm{PRP}$ had the best results in repigmentation. PRP treatment was ranked second in efficacy, whereas the Fr:CO2 was last.

In addition, we faced two difficulties with our patients in obtaining variable degree of repigmentation. The first

Table 3 Relationship between degree of improvement and sites related to each group

\begin{tabular}{|c|c|c|c|c|c|c|c|c|c|c|c|}
\hline \multirow{2}{*}{\multicolumn{2}{|c|}{$\begin{array}{l}\text { Percent } \\
\text { reduction }\end{array}$}} & \multicolumn{3}{|l|}{ PRP } & \multicolumn{3}{|c|}{$\mathrm{PRP}+\mathrm{CO}_{2}$} & \multicolumn{3}{|l|}{$\mathrm{CO}_{2}$} & \multirow[b]{2}{*}{$P$-value } \\
\hline & & Median & $\begin{array}{l}\text { First } \\
\text { quartile }\end{array}$ & $\begin{array}{l}\text { Third } \\
\text { quartile }\end{array}$ & Median & $\begin{array}{l}\text { First } \\
\text { quartile }\end{array}$ & $\begin{array}{l}\text { Third } \\
\text { quartile }\end{array}$ & Median & $\begin{array}{l}\text { First } \\
\text { quartile }\end{array}$ & $\begin{array}{l}\text { Third } \\
\text { quartile }\end{array}$ & \\
\hline \multirow[t]{4}{*}{ Location } & Face & 62.20 & 31.22 & 93.01 & 77.88 & 29.88 & 94.58 & 42.11 & 29.50 & 59.67 & 0.331 \\
\hline & $\mathrm{LL}$ & 43.63 & 38.15 & 72.03 & 33.10 & 20.12 & 59.78 & 59.69 & 41.07 & 78.31 & 0.351 \\
\hline & Trunk & 91.79 & 91.79 & 91.79 & 70.45 & 35.69 & 88.89 & 59.94 & 11.42 & 92.18 & 0.453 \\
\hline & UL & 46.12 & 23.66 & 69.32 & 70.79 & 30.83 & 90.00 & 21.18 & -3.49 & 51.47 & 0.067 \\
\hline
\end{tabular}

Abbreviations: LL, lower limb; PRP, platelet-rich plasma; UL, upper limb.

A
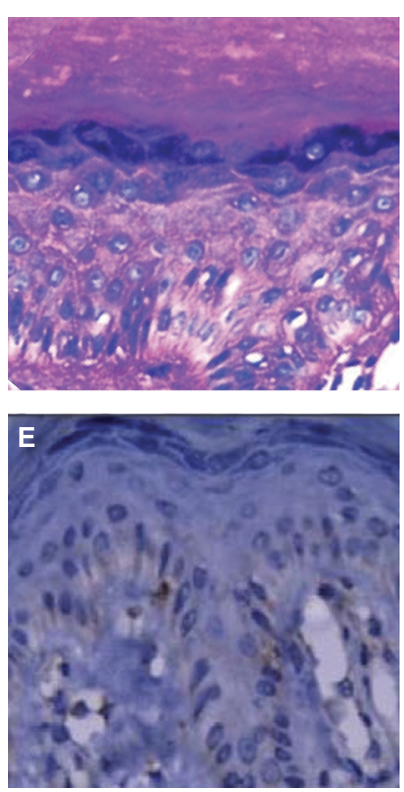

B
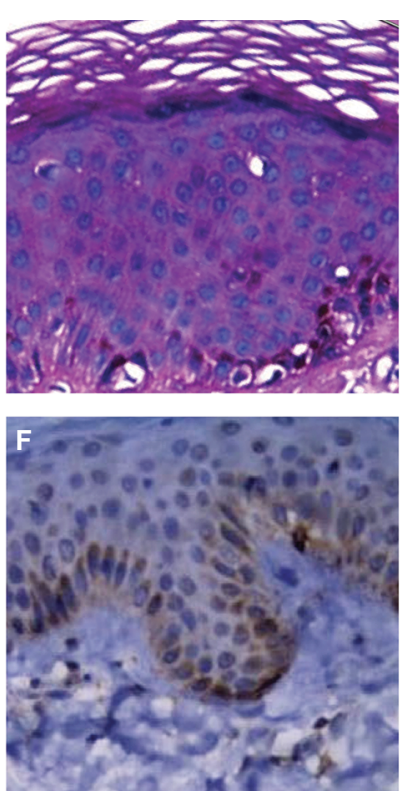

C
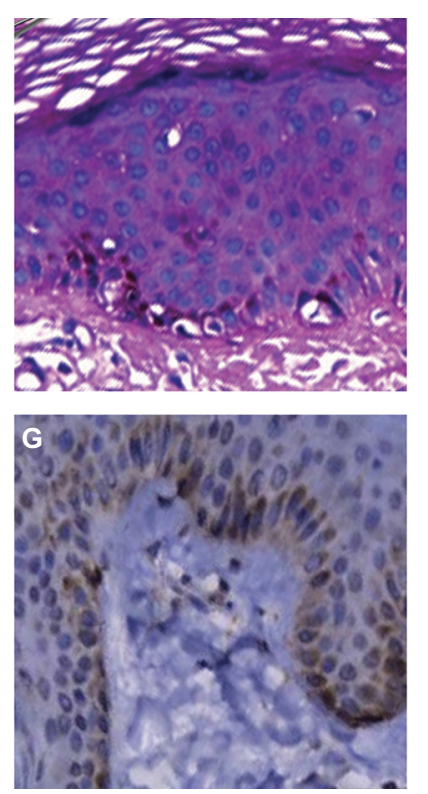

D
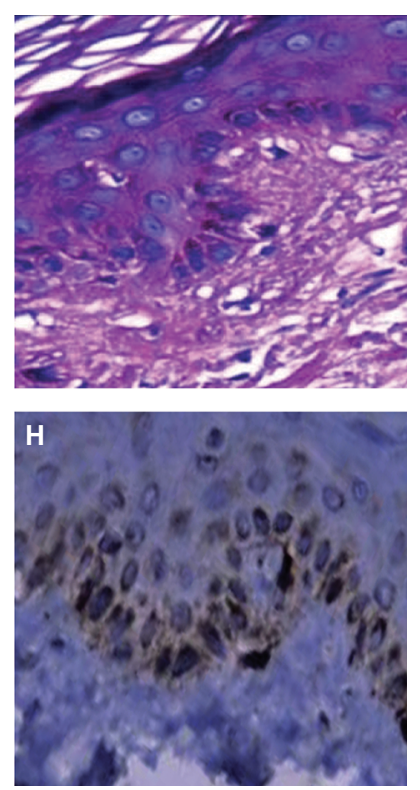

Figure 4 H\&E staining and HMB45.

Notes: $($ A) Absence of melanin pigmentation $(\mathrm{H} \& \mathrm{E}, \times 200)$ before treatment. (B) Prominent melanin pigmentation $(\mathrm{H} \& \mathrm{E}, \times 200)$ after treatment with PRP. (C) Prominent melanin pigmentation $(\mathrm{H} \& E, \times 200)$ after treatment with $\mathrm{CO}_{2}+\mathrm{PRP}$. (D) Weak melanin expression $(\mathrm{H} \& \mathrm{E}, \times 200)$ after treatment with $\mathrm{CO} 2$ alone. (E) Mild expression of $\mathrm{HMB} 45$ (PAP, $\times 200)$ before treatment. (F) Marked expression of HMB45 (PAP, $\times 200)$ after treatment with PRP. (G) Marked expression of HMB45 (PAP, $\times 200)$ after treatment with $\mathrm{CO}_{2}+$ PRP. (H) Moderate expression of HMB45 (PAP, $\left.\times 200\right)$ after treatment with $\mathrm{CO}_{2}$.

Abbreviation: PAP, Papanicolaou stain; PRP. platelet-rich plasma 
difficulty was the resistance of the patients to any other treatment modality. The second difficulty was the resistance of lesions on the hands and feet.

Regarding evaluation methods for the measurement of localized vitiligo lesions, the borders of the lesions were marked by manually tracing the lesions onto the transparent graph paper. Variations can occur originating from the thickness of the permanent marker pen, and a piece of transparent sheet is superimposed and placed over the lesion. To estimate the number of points, the number of intersections hitting the area of interest was counted. The total area of each lesion was estimated by multiplying the representative area of a point on grid by total number of points counted for the lesion and compared to planimetry.

Considering our results and potentiality of PRP, PRP can be applied as an alternative treatment modality in some recalcitrant vitiligo patients. It can also be suitable for relatively large areas of vitiligo at any site.

To the best of our knowledge, eight trials used only ablative Fr: $\mathrm{CO}_{2}$ laser in the treatment of vitiligo. ${ }^{6,7,9,14,18-21}$ One study had evaluated the effects of PRP. ${ }^{5}$ However, only one study evaluated the effects of PRP and combined Fr: $\mathrm{CO}_{2}$ with PRP on vitiliginous lesions. ${ }^{10}$

Many mechanisms may contribute to the improvement of vitiligo after $\mathrm{CO}_{2}$ laser sessions. It produces immediate tissue retraction due to the denaturation of collagen bundles. This shrinkage over treated skin surface may contribute to the narrowing of the vitiligo lesions. ${ }^{22}$

In 2016, Yuan et al found that ablative Fr: $\mathrm{CO}_{2}$ laser is more effective than the nonablative fractional laser in the treatment of NSV. ${ }^{9}$

The repigmentation in vitiligo is initiated by the activation, proliferation, and migration of melanoblasts from the outer root sheath of hair follicles. Moreover, the melanocytes migrate from the border area of vitiligo lesions into the depigmented epidermis. Based on this mechanism, we performed the technique of extension of ablative laser treatment few millimeters beyond the lesion borders. ${ }^{11}$

Further explanation of the good results of repigmentation in this study was based on the enhancement of the ultraviolet (UV) effect as the superficial layer of the skin was removed. ${ }^{23}$

Also, Hélou et $\mathrm{al}^{6}$ in 2014 found similar results to those of our study and concluded that Fr: $\mathrm{CO}_{2}$ laser followed by sun exposure could be considered as an alternative modality for the treatment of refractory vitiligo, especially in sunny regions. They explained this finding by the fact that interleukin (IL)-17, matrix metalloproteinase (MMP)-2, MMP-9, various types of cytokines, and GFs enhance migration and mitogens of melanocytes. ${ }^{11} \mathrm{Fr}$ : $\mathrm{CO}_{2}$ laser significantly increases the activity of melanocytes and their regeneration in vitiligo. ${ }^{14,20,23-25}$

Besides, in a study performed by Cunha et $\mathrm{al}^{18}$ in 2016 , the use of Fr: $\mathrm{CO}_{2}$ laser combined with betamethasone and salicylic acid solution could be a new therapeutic approach for the treatment of refractory vitiligo. In 2016, Vachiramon et $\mathrm{al}^{7}$ found higher improvement of repigmentation when they used combined Fr: $\mathrm{CO}_{2}$ laser, narrow band-ultra violet $\mathrm{B}$, and topical steroids in the treatment of recalcitrant vitiligo on hands. On the contrary, El-Zawahry et $\mathrm{al}^{26}$ found that the use of combined Fr: $\mathrm{CO}_{2}$ and NB-UVB did not show any significant advantage over the treatment with NB-UVB alone.

Limitations of the study by El-Zawahry et al were minimum number of sessions of Fr: $\mathrm{CO}_{2}$ (ie, two sessions on monthly base), small number of patients (20 patients), lack of follow-up, and lack of PRP combination. El Mofty et $\mathrm{al}^{20}$ in 2017 studied the effect of Fr: $\mathrm{CO}_{2}$ laser on vitiligo lesions. It was not associated with satisfactory clinical response, and it is too costly especially if used on large vitiligo areas.

Limitations of the study by El Mofty et al were the high cost on large vitiligo area, limited number of sessions (ie, four sessions on weekly base), low parameters, and small number of patients (10 patients) with no follow-up evaluation. Also, they could not decide whether the repigmentation was due to trauma or inverse koebener phenomenon. The lack of PRP combination is a contra verse.

PRP elicited dramatic decrease in the surface area of vitiligo with a $53.05 \%$ (median) of repigmentation.

In 2016, Ibrahim et al ascertained the effect of PRP injection on the outcome of NB-UVB therapy in NSV. There was a high statistically significant improvement in the repigmentation of the combined group (PRP with NB-UVB) compared with that in the NB-UVB group. Besides, there was a clinical variation in the degree of improvement. The difference between our results and the results of the study by Ibrahim et $\mathrm{al}^{5}$ was due to the use of combined PRP and narrow band.

Similar to our study, Abdelghani et al in 2017 compared Fr: $\mathrm{CO}_{2}+\mathrm{PRP}, \mathrm{Fr}: \mathrm{CO}_{2}$, and PRP. They concluded that the combined treatment was superior to PRP and Fr: $\mathrm{CO}_{2}$, especially in difficult-to-treat areas and refractory cases such as face and ULs. ${ }^{10}$

Limitations of this study were the small sample size (20 patients), lack of control lesions, short follow-up period, using only skin types III and IV, and limited number of sessions (four Fr: $\mathrm{CO}_{2}$ sessions). They used different schedules of sessions. ${ }^{10}$

Several mechanisms may contribute to the improvement of vitiligo lesions after PRP sessions as it contains fibrin, 
fibronectin, and vitronectin. These proteins are capable of enhancing cell adhesion between keratinocyte and fibroblast and melanocyte and act like a matrix for the formation of the epithelium. ${ }^{27-29}$

Moreover, the anti-inflammatory effect of PRP limits the release of cytokine. Subsequently, the melanocyte activity will be released and attached well to keratinocytes. ${ }^{5}$

The deficiency in unidentified GFs such as fibroblast and keratinocyte may be responsible for weakening of melanocytes attachment leading to the detachment that leads to transepidermal elimination and chronic melanocytorrhagy. ${ }^{3}$

Likewise, PRP therapy with high concentration of trophic factors in vitiligo leads to repigmentation. It acts through stimulation of proliferation, interaction of both keratinocyte and fibroblast with melanocytes, attraction, and stimulation of undifferentiated stem cells. ${ }^{28,29}$

The limitation to this study was the lack of immunohistopathological studies. The follow-up of patients was for 12 weeks for repigmentation. Hence, longer follow-up of patients is needed. Further researches are needed to evaluate Fr: $\mathrm{CO}_{2}$ and PRP in vitiligo using Fitzpatrick skin types V and VI.

\section{Conclusion}

This study suggests that the combined Fr $\mathrm{CO}_{2}$ laser with PRP with sun exposure could be used effectively and safely to treat refractory NSV. Limitations of this study were the small sample size and short follow-up period. Further intraindividual studies with larger sample size, longer follow-up periods, and immunohistochemical examinations are recommended to obtain the optimal results.

\section{Disclosure}

The authors report no conflicts of interest in this work.

\section{References}

1. Kasumagic-Halilovic E, Ovcina-Kurtovic N, Jukic T, Karamehic J, Begovic B, Samardzic S. Vitiligo and autoimmunity. Med Arch. 2013;67(2):91-93.

2. Tsuchiyama K, Watabe A, Sadayasu A, Onodera N, Kimura Y, Aiba S. Successful Treatment of Segmental Vitiligo in Children with the Combination of 1-mm Minigrafts and Phototherapy. Dermatology. 2016;232(2):237-241.

3. Whitton M, Pinart M, Batchelor JM, et al. Evidence-based management of vitiligo: summary of a Cochrane systematic review. Br J Dermatol. 2016;174(5):962-969.

4. Abuaf OK, Yildiz H, Baloglu H, Bilgili ME, Simsek HA, Dogan B. Histologic evidence of new collagen formulation using platelet rich plasma in skin rejuvenation: a prospective controlled clinical study. Ann Dermatol. 2016;28(6):718-724.

5. Ibrahim ZA, El-Ashmawy AA, El-Tatawy RA, Sallam FA. The effect of platelet-rich plasma on the outcome of short-term narrowbandultraviolet B phototherapy in the treatment of vitiligo: a pilot study. J Cosmet Dermatol. 2016;15(2):108-116.
6. Hélou J, Maatouk I, Obeid G, Moutran R, Stéphan F, Tomb R. Fractional laser for vitiligo treated by $10,600 \mathrm{~nm}$ ablative fractional carbon dioxide laser followed by sun exposure. Lasers Surg Med. 2014;46(6):443-448.

7. Vachiramon V, Chaiyabutr C, Rattanaumpawan P, Kanokrungsee S. Effects of a preceding fractional carbon dioxide laser on the outcome of combined local narrowband ultraviolet B and topical steroids in patients with vitiligo in difficult-to-treat areas. Lasers Surg Med. 2016;48(2):197-202.

8. Kim HJ, Hong ES, Cho SH, Lee JD, Kim HS. Fractional Carbon Dioxide Laser as an "Add-on" Treatment for Vitiligo: A Meta-analysis with Systematic Review. Acta Derm Venereol. 2018;98(2):180-184.

9. Yuan J, Chen H, Yan R, et al. Fractional $\mathrm{CO}_{2}$ lasers contribute to the treatment of stable non-segmental vitiligo. Eur J Dermatol. 2016;26(6): 592-598.

10. Abdelghani R, Ahmed NA, Darwish HM. Combined treatment with fractional carbon dioxide laser, autologous platelet-rich plasma, and narrow band ultraviolet $\mathrm{B}$ for vitiligo in different body sites: A prospective, randomized comparative trial. J Cosmet Dermatol. 2018;17(3): $365-372$.

11. Kumar R, Parsad D, Kanwar AJ, Kaul D. Altered levels of Ets-1 transcription factor and matrix metalloproteinases in melanocytes from patients with vitiligo. Br J Dermatol. 2011;165(2):285-291.

12. Aydin F, Senturk N, Sahin B, Bek Y, Yuksel EP, Turanli AY. A practical method for the estimation of vitiligo surface area: a comparison between the point counting and digital planimetry techniques. Eur J Dermatol. 2007;17(1):30-32.

13. Shin J, Kim M, Park SH, Oh SH. The effect of fractional carbon dioxide lasers on idiopathic guttate hypomelanosis: a preliminary study. $J$ Eur Acad Dermatol Venereol. 2013;27(2):e243-e246.

14. Shin J, Lee JS, Hann SK, Oh SH. Combination treatment by $10600 \mathrm{~nm}$ ablative fractional carbon dioxide laser and narrowband ultraviolet $\mathrm{B}$ in refractory nonsegmental vitiligo: a prospective, randomized half-body comparative study. Br J Dermatol. 2012;166(3):658-661.

15. Chan YH. Biostatistics 102: quantitative data--parametric \& nonparametric tests. Singapore Med J. 2003;44(8):391-396.

16. Chan YH. Biostatistics 104: correlational analysis. Singapore Med J. 2003;44(12):614-619.

17. Rankin G, Stokes M. Reliability of assessment tools in rehabilitation: an illustration of appropriate statistical analyses. Clin Rehabil. 1998;12(3):187-199.

18. Cunha PR, Scabine Pessotti N, Bonati Mattos C, Salai AF. New approach in the treatment of refractory vitiligo: $\mathrm{CO}_{2}$ laser combined with betamethasone and salicylic acid solution. Dermatol Ther. 2017;30(1):e12410.

19. Li L, Wu Y, Li L, et al. Triple combination treatment with fractional CO2 laser plus topical betamethasone solution and narrowband ultraviolet $\mathrm{B}$ for refractory vitiligo: a prospective, randomized half-body, comparative study. Dermatol Ther. 2015;28(3):131-134.

20. El Mofty M, Esmat S, Hunter N, et al. Effect of different types of therapeutic trauma on vitiligo lesions. Dermatol Ther. 2017;30(2):e12447.

21. El-Zawahry MB, Zaki NS, Wissa MY, Saleh MA. Effect of combination of fractional $\mathrm{CO}_{2}$ laser and narrow-band ultraviolet $\mathrm{B}$ versus narrowband ultraviolet $\mathrm{B}$ in the treatment of non-segmental vitiligo. Lasers Med Sci. 2017;32(9):1953-1958.

22. Ross EV, Yashar SS, Naseef GS, et al. A pilot study of in vivo immediate tissue contraction with $\mathrm{CO} 2$ skin laser resurfacing in a live farm pig. Dermatol Surg. 1999;25(11):851-856.

23. Awad SS. Dermabrasion may repigment vitiligo through stimulation of melanocyte precursors and elimination of hyperkeratosis. $J$ Cosmet Dermatol. 2012;11(4):318-322.

24. Wu CS, Yu CL, Wu CS, Lan CC, Yu HS. Narrow-band ultraviolet-B stimulates proliferation and migration of cultured melanocytes. Exp Dermatol. 2004;13(12):755-763.

25. Bayoumi W, Fontas E, Sillard L, et al. Effect of a preceding laser dermabrasion on the outcome of combined therapy with narrowband ultraviolet $\mathrm{B}$ and potent topical steroids for treating nonsegmental vitiligo in resistant localizations. Br J Dermatol. 2012;166(1):208-211. 
26. El-Zawahry MB, Zaki NS, Wissa MY, Saleh MA. Effect of combination of fractional $\mathrm{CO}_{2}$ laser and narrow-band ultraviolet $\mathrm{B}$ versus narrowband ultraviolet $\mathrm{B}$ in the treatment of non-segmental vitiligo. Lasers Med Sci. 2017;32(9):1953-1958.

27. Nagata MJ, Messora MR, Furlaneto FA, et al. Effectiveness of two methods for preparation of autologous platelet-rich plasma: an experimental study in rabbits. Eur J Dent. 2010;4(4):395-402.
28. Carrillo-Mora P, González-Villalva A, Macías-Hernández SI, Villaseñor CP. [Platelets-rich plasma: a versatile tool for regenerative medicine?] Plasma rico en plaquetas. Herramienta versátil de la medicina regenerativa? Cir Cir. 2013;81(1):74-82. Spanish.

29. Meytes D, Chodick G, Shalev V, Porath A. The long term risk of myelodysplastic syndromes among anemia patients: a population-based study. Leuk Res. 2012;36(3):327-330.
Clinical, Cosmetic and Investigational Dermatology is an international, peer-reviewed, open access, online journal that focuses on the latest clinical and experimental research in all aspects of skin disease and cosmetic interventions. This journal is included on PubMed. The manuscript management system is completely online and includes a very quick and fair peer-review system, which is all easy to use. Visit http://www.dovepress.com/testimonials.php to read real quotes from published authors 